PREPARED FOR THE U.S. DEPARTMENT OF ENERGY, UNDER CONTRACT DE-AC02-76CH03073

PPPL-3811

PPPL-3811

UC-70

Proof-of-Concept Experiments for Negative Ion Driver

Beams for Heavy Ion Fusion

by

L.R. Grisham, S.K. Hahto, S.T. Hahto, J.W. Kwan, and K.N. Leung

May 2003

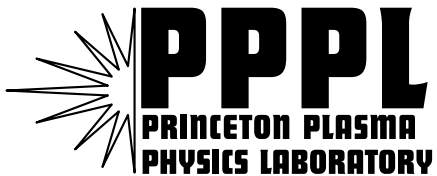

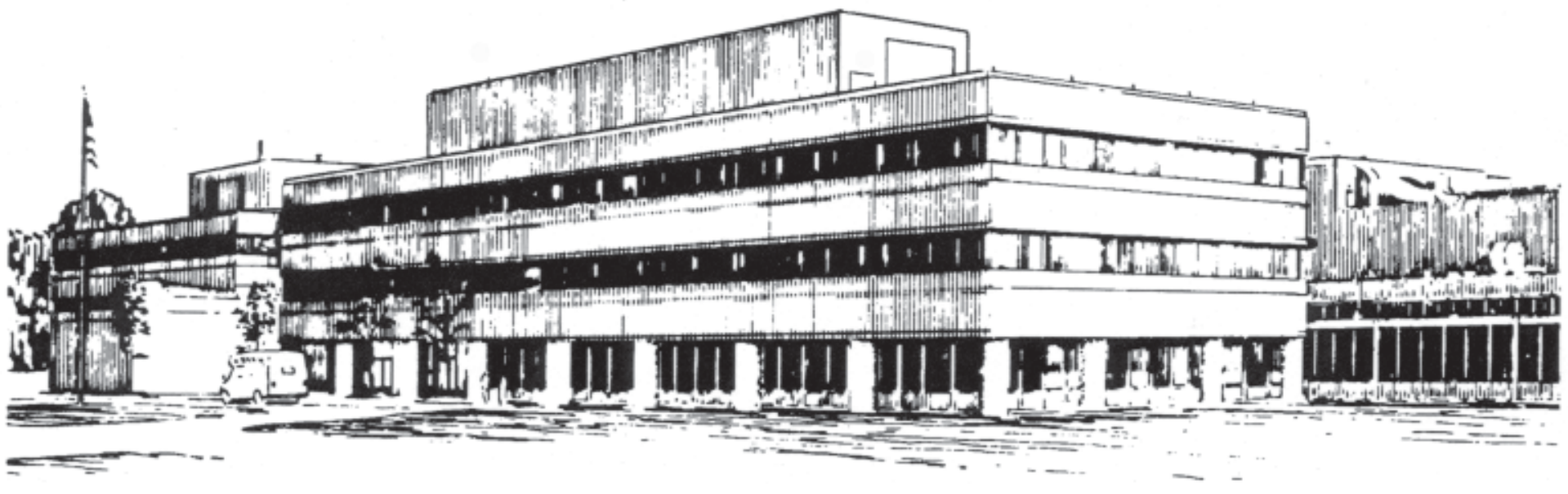

PRINCETON PLASMA PHYSICS LABORATORY PRINCETON UNIVERSITY, PRINCETON, NEW JERSEY 


\section{PPPL Reports Disclaimer}

This report was prepared as an account of work sponsored by an agency of the United States Government. Neither the United States Government nor any agency thereof, nor any of their employees, makes any warranty, express or implied, or assumes any legal liability or responsibility for the accuracy, completeness, or usefulness of any information, apparatus, product, or process disclosed, or represents that its use would not infringe privately owned rights. Reference herein to any specific commercial product, process, or service by trade name, trademark, manufacturer, or otherwise, does not necessarily constitute or imply its endorsement, recommendation, or favoring by the United States Government or any agency thereof. The views and opinions of authors expressed herein do not necessarily state or reflect those of the United States Government or any agency thereof.

\section{Availability}

This report is posted on the U.S. Department of Energy's Princeton Plasma Physics Laboratory Publications and Reports web site in Fiscal Year 2003. The home page for PPPL Reports and Publications is: http://www.pppl.gov/pub_report/

DOE and DOE Contractors can obtain copies of this report from:

U.S. Department of Energy

Office of Scientific and Technical Information

DOE Technical Information Services (DTIS)

P.O. Box 62

Oak Ridge, TN 37831

Telephone: (865) 576-8401

Fax: (865) 576-5728

Email: reports@adonis.osti.gov

This report is available to the general public from:

National Technical Information Service

U.S. Department of Commerce

5285 Port Royal Road

Springfield, VA 22161

Telephone: $1-800-553-6847$ or

(703) $605-6000$

Fax: (703) 321-8547

Internet: http://www.ntis.gov/ordering.htm 


\title{
PROOF-OF-CONCEPT EXPERIMENTS FOR NEGATIVE ION DRIVER BEAMS FOR HEAVY ION FUSION*
}

\author{
L. R. Grisham, Princeton Plasma Physics Laboratory, P.O. Box 451, Princeton, N.J. 08543 \\ S. K. Hahto, S. T. Hahto, J. W. Kwan, K. N. Leung, Lawrence Berkeley National Laboratory, \\ 1 Cyclotron Rd, Berkeley, CA 94720
}

\begin{abstract}
Negative halogen ion beams have recently been proposed as heavy ion fusion drivers. They would avoid the problem of electron accumulation in positive ion beams, and could be efficiently photodetached to neutrals if desired [1]. Initial experiments using chlorine produced a current density of $45 \mathrm{~mA} / \mathrm{cm}^{2}$ of $99.5 \%$ atomic negative $\mathrm{Cl}$ with an $\mathrm{e} / \mathrm{Cl}^{-}$ratio as low as 7:1 and good emittance.
\end{abstract}

\section{INTRODUCTION}

Driver concepts for heavy ion fusion have traditionally relied upon positive ions, which suffer the possible drawback of accumulating electrons in their deep potential wells. Negative ions would preclude electron accumulation, and if desired, could be converted to atoms by photodetachment with technically feasible lasers before entering the target chamber. The halogens bromine and iodine are the most appropriate masses for a driver, but chlorine, which has a similar electron affinity and is a gas at room temperature, is ideal for proof-of-concept experiments of the source [2].

\section{EXPERIMENTAL ARRANGEMENT}

In a process similar to that by which hydrogen forms negative ions in plasmas, halogens can be expected to form negative ions by dissociative attachment of electrons to vibrationally excited diatomic molecules. Thus, an RF driven $(12.56 \mathrm{MHz})$ source previously used for $\mathrm{H}^{-}$ production was used with $\mathrm{Cl}_{2}$ for these experiments. A movable 135 gauss magnetic filter divided the plasma into a vibrational excitation region and an extraction region. A fuller discussion of the setup and the experiments is provided in ref. [3]. Permanent magnets deflected electrons from the beam for measurement. Ion currents were measured with a secondary-suppressed Faraday cup, and a magnetic mass spectrometer analyzed the ion species. Hydrogen, with an electron affinity of $0.75 \mathrm{eV}$, requires the addition of $\mathrm{Cs}$ to produce significant negative ion currents. The halogens have electron affinities of 3.06 $-3.62 \mathrm{eV}$, so no Cs was needed.

\section{EXPERIMENTAL RESULTS}

\section{Oxygen Tests}

With an electron affinity of $1.27 \mathrm{eV}$, oxygen was a convenient non-toxic comparison gas before trying $\mathrm{Cl}$ (electron affinity of $3.61 \mathrm{eV}$ ). With $2 \mathrm{~kW}$ of RF power, a maximum of $5.7 \mathrm{~mA} / \mathrm{cm}^{2}$ of $\mathrm{O}^{-}$was extracted under the same discharge conditions which yielded $22 \mathrm{~mA} / \mathrm{cm}^{2}$ of
$\mathrm{O}^{+}$and an electron-to-negative-ion ratio of 300 . The negative/positive ion ratio of 0.25 is much better than is achievable in uncesiated $\mathrm{H}$ discharges, where it is typically of order $.01-.03$. Figure 1 shows oxygen currents extracted versus extraction voltage with $1.5 \mathrm{~kW}$ of RF and a source pressure of 10 mTorr, with $40 \%$ of the positive ions $\mathrm{O}^{+}$and $90 \%$ of the negative ions $\mathrm{O}^{-}$.

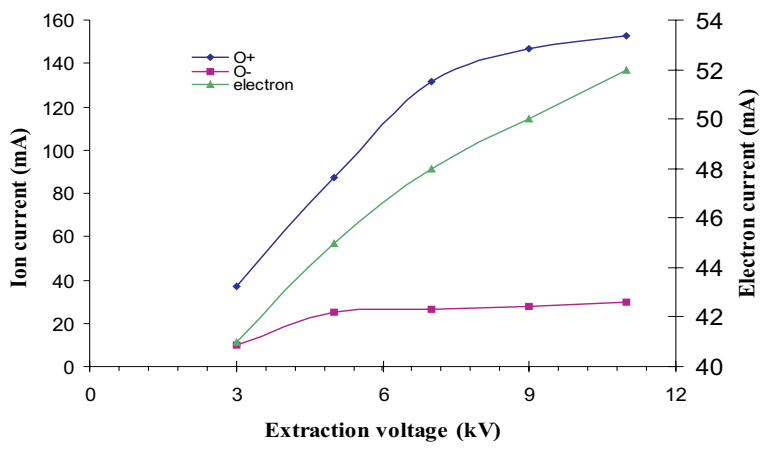

Figure 1: $\mathrm{O}^{-}, \mathrm{O}^{+}$, and $\mathrm{e}^{-}$currents vs extraction voltage.

\section{Chlorine Results}

The positive ion spectrum with chlorine was $82 \% \mathrm{Cl}^{+}$, with the rest in $\mathrm{Cl}_{2}{ }^{+}$and impurities such as nitrogen and oxygen. At the same RF power of $1.5 \mathrm{~kW}$, the negative spectrum was $99.5 \%$ atomic $\mathrm{Cl}^{-}, 0.5 \% \mathrm{Cl}_{2}^{-}$, and no detectable impurities. Figure 2 shows the $\mathrm{Cl}^{-}, \mathrm{Cl}^{+}$, and $\mathrm{e}^{-}$ current densities versus extraction voltage with arc conditions of $1 \mathrm{~kW} \mathrm{RF}$ and 25 mTorr. With chlorine's greater electron affinity, the ratios of negative/positive ions and of negative ions to electrons are much more favorable than was the case for oxygen.

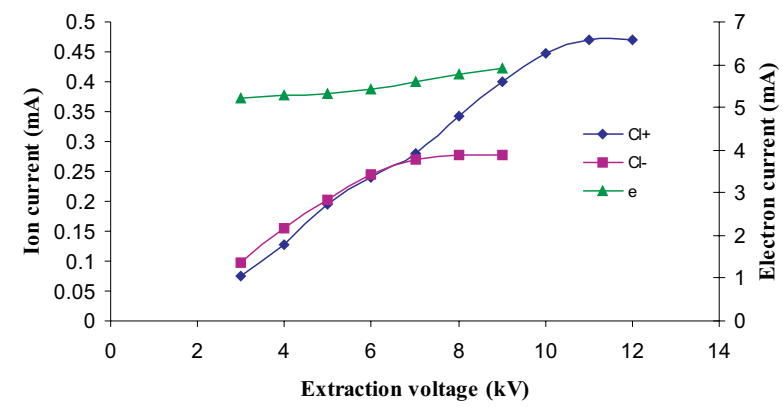

Figure 2: $\mathrm{Cl}^{-}, \mathrm{Cl}^{+}$, and $\mathrm{e}^{-}$currents vs extraction voltage.

The $\mathrm{Cl}^{-}$current density was only weakly dependent upon source pressure across the measured range of $20-$ 35 mTorr but began to decline below 20 mTorr. As was the case with $\mathrm{O}^{-}$, the $\mathrm{Cl}^{-}$current density scaled linearly with RF power, where it should be noted that the RF 
power levels given in this paper are the output power of the RF supply; the actual power coupled into the discharge plasma would have been less.

At an RF power of $2.2 \mathrm{~kW}$ (the maximum of the supply) and a source pressure of $28 \mathrm{mTorr}$, the $\mathrm{Cl}^{-}$current density was $45 \mathrm{~mA} / \mathrm{cm}^{2}$ and the $\mathrm{e}^{-} / \mathrm{Cl}^{-}$ratio was 7 . Under the same discharge conditions the $\mathrm{Cl}^{+}$current density was $53 \mathrm{~mA} / \mathrm{cm}^{2}$, so the ratio of $\mathrm{Cl}^{-}$to total positive ion current was 0.69 . Since more of the $\mathrm{Cl}^{-}$would be lost through stripping in the extractor and modestly-pumped analyzer system than would be the case for positive ion loss due to charge exchange, the actual density of $\mathrm{Cl}^{-}$in the extraction plane plasma was probably greater than $69 \%$ of the total positive ion density. Because of their large electron affinities, halogens can form ion/ion plasmas which leave very little room for electrons in phase space [4]. This is substantiated by the low $\mathrm{e}^{-} / \mathrm{Cl}^{-}$ratio that was obtained without the extractor plane magnets used to reduce the copious co-extracted electrons from $\mathrm{H}^{-}$sources. Based upon the difference in mobilities, one would expect an $\mathrm{e}^{-}$ $/ \mathrm{Cl}^{-}$ratio of about 240 instead of 7 if the electrons and ions had the same temperature, and in fact, the electron temperature was probably higher than that of the ions, which would make the expected ratio even larger. In the case of oxygen, the $\mathrm{e}^{-} / \mathrm{O}^{-}$ratio of 300 exceeded the mobility ratio of about 160 for the same temperatures, implying a higher electron temperature.

In $\mathrm{H}^{-}$volume sources, biasing the plasma grid positive relative to the plasma reduces the co-extracted electron current and can increase the extracted negative ion current [5]. With oxygen, the bias induced a noticeable effect, augmenting the $\mathrm{O}^{-}$current by $20 \%$ while diminishing the $\mathrm{e}^{-}$current by $25 \%$ as the bias increased from 0 to 15 volts; higher voltages reduced both species. In chlorine plasmas, varying the bias from 0 to 35 volts had almost no effect upon the $\mathrm{Cl}^{-}$current, and reduced the $\mathrm{e}^{-}$by less than $5 \%$. This probably reflects the scarcity of electrons in the ion/ion chlorine plasma at the extractor plane.

Figure 3 shows $\mathrm{Cl}^{-}$and $\mathrm{e}^{-}$currents as functions of source pressure. The $\mathrm{e}^{-}$current is much more sensitive to pressure than the $\mathrm{Cl}^{-}$current, declining strongly with pressure. This may be due to a decrease in the extractorregion electron temperature at higher pressure, which would reduce the electron mobility.

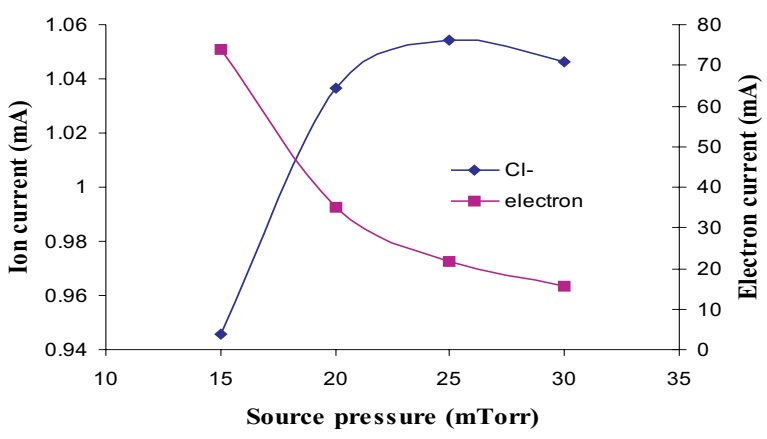

Figure 3: $\mathrm{Cl}^{-}$and $\mathrm{e}^{-}$versus pressure
Figure 4 shows the $\mathrm{Cl}^{-}$and $\mathrm{e}^{-}$extracted currents as a function of the distance from the plasma grid of the magnetic filter which partitions the plasma. The electron current is significantly more sensitive to filter position than is the $\mathrm{Cl}^{-}$current The rapid rise in electron current for the largest distances from the extraction plane might be partly due to the fact that this movable filter may have allowed leakage of energetic electrons around its edges; with more distance, a greater number of these electrons may have reached the axis, where the extraction aperture was located. Alternatively, the filter may have been positioned too close to the RF antenna, allowing electron heating beyond the filter.

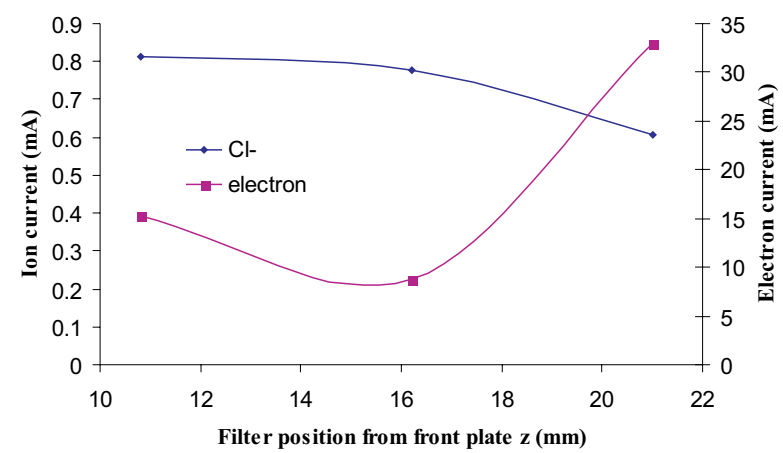

Figure 4: $\mathrm{Cl}^{-}, \mathrm{e}^{-}$versus filter distance from plasma grid

A pepper pot measurement was done to obtain an approximate measure of the effective beam temperature in the directions transverse to the beam propagation axis. Measurements were done in the directions parallel and perpendicular to the electron deflection magnetic field. The effective beam temperature is larger in the perpendicular direction due to the magnetic deflection of the ions. The effective temperatures in the perpendicular direction were $0.5 \mathrm{eV}$ for both $\mathrm{Cl}^{-}$and $\mathrm{Cl}^{+}$; in the parallel direction they were $0.3 \mathrm{eV}$ for $\mathrm{Cl}^{-}$and $0.2 \mathrm{eV}$ for $\mathrm{Cl}^{+}$.

\section{Implications for Heavier Halogens}

The more massive halogens, bromine (mass 79 and 81 ) and iodine (mass 127), are most likely to fit the mass requirements presently being considered for heavy ion driver beams. Experiments with these elemental feedstocks will require ion sources at moderately elevated temperatures (the boiling points of $\mathrm{Br}$ and $\mathrm{I}$ are $59 \mathrm{C}$ and $114 \mathrm{C}$, respectively. Since they should form negative ions through the same mechanism as $\mathrm{Cl}$ (dissociative attachment of electrons to vibrationally excited dimers), results with the heavier halogens should be similar to the $\mathrm{Cl}$ experiments. The achievable current density at a given $\mathrm{RF}$ power may be somewhat lower for $\mathrm{Br}$, with an electron affinity of $3.36 \mathrm{eV}$, and for I, with an electron affinity of $3.06 \mathrm{eV}$, than they were for $\mathrm{Cl}$. However, this should not be a problem if the observed linear scaling of negative ion current density with RF power continues to higher levels. For instance, the $45 \mathrm{~mA} / \mathrm{cm}^{2}$ of $\mathrm{Cl}^{-}$found at $2.2 \mathrm{~kW}$ extrapolates to about $100 \mathrm{~mA} / \mathrm{cm}^{2}$ at $5 \mathrm{~kW}$, which was the planned power level for this source before problems were found with the intended power supply. 
Although one would normally expect the co-extracted electron component to be greater for $\mathrm{Br}$ and $\mathrm{I}$ than for $\mathrm{Cl}$, both because of their greater mass and their somewhat lower electron affinities, this may be compensated to an unknown degree by a competing effect: the greater mass of $\mathrm{Br}^{+}$and $\mathrm{I}^{+}$compared to $\mathrm{Cl}^{+}$. The addition of cesium to $\mathrm{H}$ sources not only increases the production of $\mathrm{H}^{-}$; it also significantly reduces the co-extracted electron current. The electron suppression is thought to occur because the massive (133 amu) $\mathrm{Cs}^{+}$in plasma near the extraction plane provides a drag on the flow of the low energy electrons in that region to the extraction meniscus. If this hypothesis is correct, then the same effect could be expected to occur in halogen plasmas. Thus, the low level of electrons co-extracted with $\mathrm{Cl}^{-}$might be partly attributable to the mass ( $37 \mathrm{amu}$ ) of $\mathrm{Cl}^{+}$, in which case the electron suppression could be expected to be even more favorable for $\mathrm{Br}$ and $\mathrm{I}$. Iodine has almost the same mass as cesium ( 127 versus 133 ), and the density of $\mathrm{I}^{+}$in an iodine plasma should be significantly higher than the density of $\mathrm{Cs}^{+}$in a dominantly hydrogen plasma.

$\mathrm{H}^{-}$ion sources commonly remove their much more abundant co-extracted electrons by mounting permanent magnets inside the extractor grid to deflect the electrons onto the extractor aperture walls while they are still at low energy. The effect upon the optics of the $\mathrm{H}^{-}$is small because of its much greater mass. While this technique works well, the space required for the placement of magnets reduces the maximum grid transparency available to a multi-aperture beamlet array.

This same technique could be used for multi-aperture $\mathrm{Br}^{-}$or $\mathrm{I}^{-}$beamlet arrays; because they are both much more massive than $\mathrm{H}^{-}$, the effect upon ion optics should be even less than in today's $\mathrm{H}^{-}$sources. However, it might not be necessary if the electron component remains as small as was found with $\mathrm{Cl}$. Unlike the current applications of multi-aperture $\mathrm{H}^{-}$sources, which must dump the electrons because the beam pulses last for seconds, and the electrons would otherwise reach the full acceleration energy, heavy ion fusion sources will fire microsecond pulses, and the electrons could be dumped further down or after the injector before they reach the main accelerator, since the short pulses and low duty factor would limit the heat load.

\section{CONCLUSION}

Heavy negative ions would have some appealing characteristics as driver beams for inertial confinement fusion [1]. Because the halogens have large electron affinities they are the most natural candidates for high brightness heavy negative ion sources [2]. A proof-ofconcept experiment was conducted using chlorine, which can be used in a room temperature source, and should be a good surrogate for bromine and iodine, which have masses more appropriate for driver beams, but require moderately elevated source temperatures.
In contrast to ion sources using hydrogen, which has an electron affinity of $0.75 \mathrm{eV}$, it was not necessary to add cesium to obtain high negative ion current densities. In order to evaluate the effect of electron affinity upon yield, the source was first operated with oxygen (electron affinity of $1.27 \mathrm{eV}$ ), producing an $\mathrm{O}^{-}$yield of 5.7 $\mathrm{mA} / \mathrm{cm}^{2}$, an $\mathrm{O}^{-}$to positive ion ratio of 0.25 , and an electron-to-negative-ion ratio of 300 . Chlorine (electron affinity of $3.62 \mathrm{eV}$ ) yielded a negative ion spectrum which was $99.5 \% \mathrm{Cl}^{-}, 0.5 \% \mathrm{Cl}_{2}^{-}$, and no detectable impurities. Under the most optimized conditions, the $\mathrm{Cl}$ negative ion current was $69 \%$ of the total positive ion current, suggesting a mostly ion-ion plasma near the extraction plane (probably with an even higher fraction of negative ions than the current ratios indicate, because of higher negative ion loss rates at low energy). Under these conditions, the electron current to negative chlorine ratio was 7 , much less than the mobility ratio of about 240 for equal temperatures, which also suggests the presence of few electrons in the extraction plane plasma. Biasing the plasma grid positive relative to the plasma reduced coextracted electrons and increased $\mathrm{O}^{-}$with oxygen, but had little effect with chlorine, again suggesting a scarcity of electrons in the extraction plane plasma. Preliminary emittance measurements gave effective beam temperatures of $0.2 \mathrm{eV}$ for $\mathrm{Cl}^{+}$and $0.3 \mathrm{eV}$ for $\mathrm{Cl}^{-}$in the direction parallel to the electron analysis magnets, and 0.5 $\mathrm{eV}$ for both species in the direction perpendicular to the analysis field; these values appear acceptable for drivers.

In both oxygen and chlorine plasmas, the negative ion current density scaled linearly with RF supply output. At the maximum RF supply power of $2.2 \mathrm{~kW}$, the $\mathrm{Cl}^{-}$current density was $45 \mathrm{~mA} / \mathrm{cm}^{2}$, which would extrapolate to about $100 \mathrm{~mA} / \mathrm{cm}^{2}$ at $5 \mathrm{~kW}$ (the intended level before problems with the RF supply). This level is fully adequate for driver applications. Since halogens permit negative ion current densities similar to positive ion densities, the extractable current densities of heavier driver ions such as $\mathrm{I}^{-}$or $\mathrm{Cs}^{+}$will depend upon the extraction voltage which can be applied. This will be a function of the extractor design, and not the polarity of the ion. Thus, achievable ion source parameters appear acceptable for halogen negative ion driver beams.

\section{REFERENCES}

[1] L. R. Grisham, Nucl. Instrum. \& Meth. A464(2001) 315.

[2] L. R. Grisham, Fus. Sci. \& Tech. 43 (2003) 191.

[3] S. K. Hahto, S. T. Hahto, J. Kwan, K. N. Leung, L. R. Grisham, Rev. Sci. Instr, in press (2003).

[4] M Bacal, H. Doucet, IEEE Trans on Plas. Sci. PS-1 (1973) 91.

[5] K. Leung, K. Ehlers, R. Pyle, Rev. Sci. Inst. 56 (1985) 11

* Work supported by U.S. Department of Energy 


\section{External Distribution}

Plasma Research Laboratory, Australian National University, Australia

Professor I.R. Jones, Flinders University, Australia

Professor João Canalle, Instituto de Fisica DEQ/IF - UERJ, Brazil

Mr. Gerson O. Ludwig, Instituto Nacional de Pesquisas, Brazil

Dr. P.H. Sakanaka, Instituto Fisica, Brazil

The Librarian, Culham Laboratory, England

Mrs. S.A. Hutchinson, JET Library, England

Professor M.N. Bussac, Ecole Polytechnique, France

Librarian, Max-Planck-Institut für Plasmaphysik, Germany

Jolan Moldvai, Reports Library, MTA KFKI-ATKI, Hungary

Dr. P. Kaw, Institute for Plasma Research, India

Ms. P.J. Pathak, Librarian, Insitute for Plasma Research, India

Ms. Clelia De Palo, Associazione EURATOM-ENEA, Italy

Dr. G. Grosso, Instituto di Fisica del Plasma, Italy

Librarian, Naka Fusion Research Establishment, JAERI, Japan

Library, Plasma Physics Laboratory, Kyoto University, Japan

Research Information Center, National Institute for Fusion Science, Japan

Dr. O. Mitarai, Kyushu Tokai University, Japan

Dr. Jiangang Li, Institute of Plasma Physics, Chinese Academy of Sciences, People's Republic of China

Professor Yuping Huo, School of Physical Science and Technology, People's Republic of China

Library, Academia Sinica, Institute of Plasma Physics, People's Republic of China

Librarian, Institute of Physics, Chinese Academy of Sciences, People's Republic of China

Dr. S. Mirnov, TRINITI, Troitsk, Russian Federation, Russia

Dr. V.S. Strelkov, Kurchatov Institute, Russian Federation, Russia

Professor Peter Lukac, Katedra Fyziky Plazmy MFF UK, Mlynska dolina F-2, Komenskeho Univerzita, SK-842 15 Bratislava, Slovakia

Dr. G.S. Lee, Korea Basic Science Institute, South Korea

Institute for Plasma Research, University of Maryland, USA

Librarian, Fusion Energy Division, Oak Ridge National Laboratory, USA

Librarian, Institute of Fusion Studies, University of Texas, USA

Librarian, Magnetic Fusion Program, Lawrence Livermore National Laboratory, USA

Library, General Atomics, USA

Plasma Physics Group, Fusion Energy Research Program, University of California at San Diego, USA

Plasma Physics Library, Columbia University, USA

Alkesh Punjabi, Center for Fusion Research and Training, Hampton University, USA

Dr. W.M. Stacey, Fusion Research Center, Georgia Institute of Technology, USA

Dr. John Willis, U.S. Department of Energy, Office of Fusion Energy Sciences, USA

Mr. Paul H. Wright, Indianapolis, Indiana, USA 
The Princeton Plasma Physics Laboratory is operated by Princeton University under contract with the U.S. Department of Energy.

\author{
Information Services \\ Princeton Plasma Physics Laboratory \\ P.O. Box 451 \\ Princeton, NJ 08543
}

Phone: 609-243-2750

Fax: 609-243-2751

e-mail: pppl_info@pppl.gov

Internet Address: http://www.pppl.gov 